\title{
Social Mechanisms of Influence on the Sociocultural Practices of Migrants
}

\author{
E. V. Chumak*, D. N. Yadransky \\ Ural State University of Economics, Yekaterinburg, Russia \\ "Corresponding author. Email: lena22021977@yandex.ru
}

\begin{abstract}
The article deals with the issue of sociocultural distance arising between migrants and the sociocultural the environment of the host city. It has been found that at the present there is a negative tendency connected with incorporation of migrants from the urban environment into ethnic communities where their sociocultural practices acquire demonstrative character. These practices act as an irritant to the local population, forming a social distance and outlining identification of "friend-or-foe". The specified situation has formed a research problem, the relevance of which can be explained by the necessity of developing social technologies aimed at reduction of socio-cultural distinctions between migrants and the city environment. According to the results of the theoretical analysis as well as the analysis of authors' research, a number of tactical social tools, capable of providing the start of the first stage of socio-cultural rapprochement, that is reduction of social distance, were proposed. Also, the authors' vision of a urban environment model in a sociocultural aspect is offered; the place of each of its participants in the process of sociocultural interaction is specified. The authors point out the necessity of direct participation of municipalities in solving the problem of the migration inflow because of its potential danger for the effective development of the social city environment. The authors state that one of the problems complicating integration of migrants into the socio-cultural environment of the city is their concentration around the "core" of the community which sets the behavioral norms and values. The paper contains practical instructions for the concepts of events and measures aimed at reducing the cultural distance and the influence of the social "core" of the migrant environment on the behavioral practices of migrants.
\end{abstract}

Keywords: migrants, socio-cultural environment, urban space, influence, conflicts, cultural differences.

\section{INTRODUCTION}

The modern information space rather ambiguously characterizes the situation with influx of migrants to the Russian Federation. On the one hand, in a positive context, as the main source of personnel inflow for lowand medium-skilled jobs, and on the other hand, in a negative context, as a source of cross-cultural and interethnic conflicts. It shall be noted that in a positive context, this thesis is more characteristic of macroeconomic discourse, while in a negative one - for the level of specific territories and municipalities. The situation has become especially aggravated recently, when the cultural gap between the migrant and the host country began to increase significantly (due to a sharp reduction in the inflow of migrants from culturally close countries). In this direction, the problem associated with some cultural "leveling" of migrants by bringing their cultural model closer to the prevailing one on the receiving territory deserves attention. It shall be noted that the formed vector of migration - internal migration in the direction of "village-large city" also requires similar attention. In this case, sociocultural differences will be somewhat less, but they also turn out to be quite sensitive.

\section{MATERIALS AND METHODS}

To characterize the scale of this problem, the author conducted a study of the social practices of migrants, their values and individual cultural norms, using the method of semi-structured interviews. The study was conducted between 2015 and 2020. A total of 79 migrants from various post-Soviet countries were interviewed. The sample structure was guided by the availability of respondents and general compliance with the structure of migrants from European (Ukraine, Belarus, Moldova) and Central Asian (Tajikistan, Uzbekistan, Kyrgyzstan) republics. The study was conducted by direct interviews. This also allowed the researcher to assess the level of language literacy, the ability to think in Russian, as well as the behavioral aspects of the respondent. As methods 
for systematizing the results obtained, we used the matrix analysis developed in the course of the study by E. Chumak, based on the author's codification of the answers received and their cross-comparison carried out in the form of a matrix. This approach made it possible to structure a qualitative sociological study and conduct a qualimetric description of the results obtained. The study methods were as follows: the study of special literature, the results of secondary sociological studies. Processing of the results was based on the logic of induction. The author's recommendations were formed by synthesizing existing developments in the field of social technologies. The authors consider the main purpose of the study to be development of socio-technological solutions for building work to reduce cultural differences and approximate the socio-cultural characteristics of immigrants from Central Asia and residents of large cities of the Sverdlovsk region (primarily Yekaterinburg and satellite cities). This makes it necessary to solve the problems associated with formulation of key differences and development of a social mechanism of cultural influence on migrants, in order to prevent conflicts between migrants and representatives of the host country on the basis of sociocultural differences. A special task seems to be development of recommendations for working with the existing ethnic enclaves, which is a more difficult task in comparison with those described.

\section{RESULTS AND DISCUSSION}

Considering the contemporary problems of migrants, it shall be said that their description in the references is found in a number of sources. Wherein, the social problems of migrants from villages and migrantsforeigners often coincide. So, as O. Lushnikova describes [1]: "Half of the rural residents, when moving to the city, experience housing difficulties ...", "The second difficulty of migrants from the countryside is the problem of employment. Migrants, in contrast to the local population, more often agree to "non-prestigious" jobs associated with unskilled manual labor (laborers, porters, cleaners)" [1]. Without getting hung up on listing the problems of migrants, you can also cite the problems identified by other authors. V. Mukomel points out that newcoming "population often encounters various violations in the labor sphere: unofficial employment, non-payment or incomplete payment of wages, unpaid leave or sick leave, lack of health insurance, and etc." [2]. The causality of migration for internal and external migrants is the same. So A. Tomaska calls the low level of employment and low incomes the main reason for migration of the indigenous small-numbered peoples of the North from their places of compact residence to urban settlements [3, p. 142]. According to the available author's data, a situation similar to that described by A. Tomaska fully coincides with the problems of immigrants from Central Asia (to a lesser extent, from Moldova). However, this cannot but affect the axiosphere of the migrant. The researcher cites the opinion of $\mathrm{L}$. Korel [4], arguing that this fact "testifies to the difficult socio-economic, living conditions in places of compact residence..." assuming that "such a move is an act of despair and an indicator of catastrophic adaptation - the need for adaptation and the inability to carry it out, accompanied by the collapse of the internal structure (author of the outcome society structure)" [3, p. 142].

Social portraits of migrants also coincide. V. Mukomel calls a young man with a secondary education who is married as a typical migrant [2]. The increase in recent years in the proportion of young male migrants (for small peoples of the North) is noted by A. Tomaska [3, p. 142]. The similarity of their social and labor practices shall also be noted. Migrants are guided by earnings, regardless of the work schedule and working conditions, work intensively, with irregular work schedules [2]. They suffer a large number of inconveniences: social and domestic (life in rented apartments, rooms, temporary construction structures, cold unfinished objects; they spend a lot of time on the way to work); physical (exhausting work schedule, hard physical labor in the construction industry, and etc.) [5]. All of the above creates a rather weak sociocultural space for migrants to internalize the norms and values of the host country. Moreover, as O. Lushnikova rightly notes, "On the one hand, migrants from the countryside are included in a common socio-cultural space with common values, which serves as a factor facilitating the process of adaptation in the city; but, on the other hand, they are forced to join the already established system of social relations, which inevitably leads to a crisis of identity" [6]. For foreign migrants from a different sociocultural environment, all that has been said has an even greater level of polarization of the problem.

One of the few differences that characterize the sociocultural space of external and internal migrants is the fact that, according to Y. Bychenko and V. Shibanov, "the majority of internal migrants remain within their FDs (federal districts). Among the rural population, the share of "close" migration is noticeably higher than among the urban population $-75-85 \%$ versus $55-81 \%$ depending on the federal district: the rural population is more focused on intraregional migration to nearby cities, to regional and district centers [7]. The second difference we would call the nature of inclusion in labor and economic activities in the host territories. So, if for rural migrants employment through relatives is more typical, for external migrants - employment through an ethnic enclave or diaspora. In fact, in both cases, the cultural gap is obvious, but in the second one, there is a great distance.

The issue of smoothing out (or preserving) these cultural differences occurs in the urban environment. As D. Brazevich notes: "an urban community, being the same social organism as an ethnos, can include its own "code of honor", or a set of cultural and value norms and 
rules of behavior that are formed on the basis of the majority of its members..." [8]. However, if the villagers, joining the urban socio-cultural environment, transform it to a lesser extent: slightly slowing down the pace of life, reducing the social distance, but gradually assimilate. Migrants from Central Asia have insignificant signs of assimilation into it, mainly creating a new "suburban environment" that is being formed in places of their compact residence (in ethnic enclaves). In this case, it is no longer virtual (according to D. Brazevich), but a real ethnos that has a social impact on the urban environment. From the point of view of F. Riggs "an obvious sign of ethnicity is its relationship with individual consciousness and obligations" (Quote from: [9, p. 72]). Agreeing with this thesis, it is important to note that the above-mentioned marginalizing circumstances lead to deformation of certain sociocultural norms of immigrants from Central Asia. In this context, this thesis is a continuation of F. Riggs' thought that "ethnicity is not a constant of human existence given by history, but some cultural variable created by the community and accepted by the individual [10]. However, under stress from a number of the listed external factors, a significant number of migrants experience a social conflict, which is implemented through isolation from the environment. In this context, the diaspora shall ensure "that the group preserves its original ethnic identity while simultaneously identifying itself with the "soil", that is, with the surrounding urban environment" [8]. However, often in Russian conditions, ethnicity turns into a category described by E. Hobsbawm as being formed by people who use it to implement their own particular interests in order to gain "access to state and administrative posts, which in many similar countries represent the most important path to wealth and accumulation of capital for those who do not possess the skills of modern entrepreneurship" [11; 9, p. 72]. In fact, in our studies, this idea was confirmed in the fact that the word "diaspora" is practically not mentioned by immigrants from Central Asia (it is said about fellow countrymen), while immigrants from the republics of Transcaucasia indicate precisely the role of the diaspora in the process of settling.

Authors who have studied the integration of migrants into the urban environment indicate that ".... the texts we have studied do not form a positive image of the community, but, on the contrary, represent a negative image and encourage ... to be wary of visitors" [9, p. 182]. In our opinion, all of the above leads to the idea that the efficiency of the social mechanisms used at the present stage for integrating migrants into the social environment of the host city is critically low. This is true for both internal and external migrants and has general implications. Since it is difficult to argue with the thesis of D. Brazevich that: "the constant interaction of the individual with other members of the community leads to the fact that he/she "absorbs" general sociocultural norms" [8], we see it as very important to create conditions for such interaction, given the degree (duration) of employment of this category of persons, as well as their social status.

In the process of implementing the strategy of integrating a migrant into the urban environment, the theory offered by D. Karanov [12] is of interest, according to which a social community is formed around its own set of rules, called by the researcher as the "sociocultural core". When assessing the "quality" of such a "core", it is important to consider that R. Merton's thesis that: "an activity originally conceived as a means of achieving a goal becomes an end in itself. In such groups, the original goals are forgotten and the ritualistic adherence to institutionally prescribed behavior takes on the character of genuine obsession [13]. In these conditions, the external practices of migrants often act as a source of conflict between the migrants themselves and representatives of the receiving side. Wherein, the same external practices (social behavior, dress style, and etc.) are an important indicator of successful primary integration.

In this case, we believe that the elements that make up the inner core, described by D. Karanov as "stereotypical attitudes regarding lifestyle, appearance, linguistic characteristics, cultural values, ways of spending free time, and etc." [12] are of different orders. So, if these stereotypical attitudes are predominantly attributive, then cultural values constitute the deep basis of the existence of an ethnos. Wherein, it is the attributive elements that cause the main dissatisfaction (they act as the basis for the identification of "friend or foe") among the receiving side, dissatisfaction with migrants (migration) was expressed to respondents who did not have attributive (and even cultural) differences. We associate the latter with the fatigue of the urban environment from migration as an established social phenomenon. The latter, in our opinion, prevents the rapprochement of social groups and complicates cultural exchange. Accordingly, one of the key tasks is to reduce the social fatigue of the host side by reducing "demonstrative ethnicity". In this aspect, we are talking only about attributive, and not about socio-cultural characteristics. Within the framework of these actions, practically the only action available today is the passing of an exam in the Russian language and history of Russia by migrants upon receipt of a patent. However, this exam is passed only by persons applying for it, despite the fact that a significant part of migrants (primarily women, old people) move to the territory of the Russian Federation for other reasons. In this case, we actually have in the urban space two formed social groups with selfidentification "friend or foe" (foreign migrants and the local population), a poorly delineated stratum of rural migrants, which occupies an intermediate position is a separate sub-group. If the social integration of rural migrants within the framework of the first generation 
seems to be quite real without use of special social techniques, then the solution of the problem of rapprochement between the host society and migrants seems to us much more difficult.

First, migrants in the modern social space of the city also do not represent an integral social group, since they come from different republics, are engaged in various types of professional activities (depending on the country of origin) and have significant linguistic differences.

Secondly, within the framework of the policy of ethnic multiculturalism implemented in the Russian Federation, it is possible to use only indicative mechanisms of influence, which, in our opinion, in conditions of enclave residence and established social practices, may require a long period.

Thirdly, there is a part of migrants (mainly women with children) who are largely excluded not only from the social practices of the host country, but are also limited within the framework of social practices in the enclave (mainly within the family), which additionally limits the tools of influence.

The city itself, in solving the listed problems, has extremely limited capabilities, which, however, deserve attention:

- early inclusion of children in the urban environment, by involving them in preschool institutions. Wherein, we are aware of the low interest of migrants (due to the specifics of family education) in this form of education and the overload of the system with children of the citizens of the Russian Federation. However, an option of attraction is to issue the children of migrants with a kind of season tickets to prepare for school on the basis of a preschool educational institution (with appropriate funding). Such measures not only can, but shall also become part of integration of migrant children in preparing the latter for entering school;
- development of tools for active propaganda among migrants of the values of Russian culture and the Russian model of life. Wherein, propaganda shall ensure coverage of the maximum possible number of migrants, primarily girls and women, revealing to them the possibilities of self-realization within the framework of the Russian culture. The sources of such propaganda shall, along with educational organizations, be the corresponding religious figures of the secular Islamic republics (Bashkortostan, Tatarstan);

- development and support of the diasporas of the Central Asian peoples, creation of resource centers for social adaptation on their basis, with conduct of educational work among migrants within the framework of approved (agreed) programs. Such activities shall be aimed at enhancing the attraction of migrants to education and transition to employment in more productive (qualified) sectors of the economy;

- we do not exclude the expediency of developing excursions in the languages of migrants for municipal museums in order to fully involve migrants in the cultural life of the host territory;

- introduction of a recommendatory ban for labor migrants working in municipal enterprises, as well as in contractors performing activities on the instructions of the municipality to use during working hours (at work) conversations in the language of the country of origin;

Using the fairly fair thesis of D. Brazevich, we consider it necessary to participate in formation of the cultural nucleus of migrants. The latter is possible, among other things, by attracting representatives of these ethnic groups to government bodies in positions related to work with migrants. We agree with the opinion of $\mathrm{E}$. Balatsky and N. Yekimova, who assert: "the fate of the economy, people and country depends on a high-quality

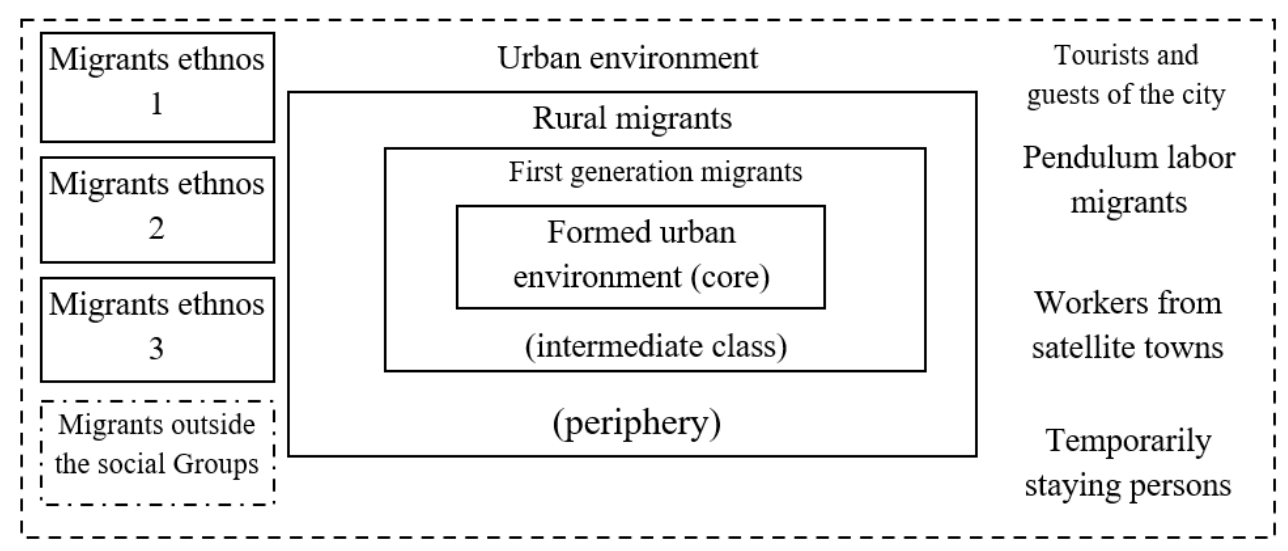

Figure 1. Model of an urban social environment, a migration-attractive city 
system of public administration" [14]. Along with other means, the correction of existing deviations by methods of external influence has a positive social effect on development of host territories [15].

We associate the need for financial costs for working with migrants due to the fact that the urban environment turns out to be quite compact, due to which the interaction of stable social formations existing on different sociocultural bases in the short or long term will certainly lead to contradictions or conflicts. We would represent this social structure in the form shown in Fig. 1

In Fig. 1 the frame "migrants ethnos 1, 2, 3" (the number is conditional) shows migrants who have formed social groups or enclaves. The dashed line shows incorporated migrants (mainly from countries with a similar culture). Despite the fact that we agree with the thesis of D. Brazevich that: "considering the differentiated nature of the urban society, it can be assumed that there are social groups "close" to the sociocultural core and "remote" from it" [8]. Wherein, we believe that at the present stage there are social groups that are practically not connected with the urban environment. Such groups are shown in Fig. 1 - "migrants ethnos" and are separated by a solid line by the boundaries of the enclave (which essentially means the isolation of the specified social group).

4. Conclusions. From the above, we can conclude that in the urban environment there is a potential threat of collisions, social spaces, indicated in Fig. 1. With a significant socio-cultural, linguistic and value-normative distance, the resolution of contradictions seems to us unlikely. In this regard, we offer an artificial convergence as a solution. As D. Karanov rightly notes, "The sociocultural structure of an urban community shall include the core and a set of social groups that identify with this community, but have different potential to influence the complex of cultural and value norms and attitudes inherent in it" [12]. Therefore, each migrant environment (in Fig. 1 "ethnos") can be represented in a form similar to the urban environment itself (core-periphery). In our opinion, some of the migrant communities not only have their own core that does not depend on the urban community, but it is also logical to assume that this "core" is not interested in its own weakening. In order to preserve their own influence, it is important for the representatives of the "core" to maintain a sense of distance between the representatives of the community and the local population (urban environment). In this case, we believe that the main tool for weakening the core (which is necessary to reduce the distance) is to consider the transformation of consciousness in the periphery. For this, there is a need to actualize the work of the city with the migrant environment directly (not only through the established channels of diaspora communities). Wherein, the activity of the institutional associations of migrants is also important, provided that their activities are built in accordance with the interests of development of the urban socio-cultural environment and the convergence of social distance.

We see the following as a set of tactical actions that can be implemented both directly and with the help of diasporas:

- inclusion of migrants in the social life of the city through the activation of the work of the diasporas in the context of mass city events, holidays (city-wide, non-ethnic);

Improvement of work on social patronage aimed at alternative support (alternative to the communities) of migrants and their families, provided that not only a male migrant, but also a female migrant is included in the life of the city;

Work to limit (prevent) the formation of territorial enclaves by promoting the rental of municipal housing among migrants;

Promotion of cultural values of Russian culture into the social environment of migrants. For this, a number of actions are offered, namely: "city dress code"; "Cultured citizen", "acquaintance with the city".

The above promotions deserve some attention. These actions, first of all, shall be of the nature of propaganda and promote these actions, ensuring involvement in them not only of representatives of migrant communities, but also of urban residents representing the social periphery. Each of these concepts can become socially significant for individual migrant groups and can influence external social practices without affecting the cultural core of the migrant's personality. The latter, in our opinion, can reduce the distance in identifying "friend or foe" and create the preconditions for further convergence of the social environment. Wherein, at this stage, we are not talking about rapprochement as such, but we are considering only the first stage of possible rapprochement, which we call "reducing the social distance."

Working with the personality of a migrant, with his/her socio-cultural space is a complex, multifaceted stage, the implementation of which within the framework of the first generation does not always seem possible and expedient). However, in order to solve this problem within several generations, it is necessary to strengthen the educational influence of the school, at least in those places where children of migrants dominate.

\section{REFERENCES}

[1] O.L. Lushnikova, Difficulties of adaptation of rural migrants in the urban environment (on the example of Khakassia) in: Scientific Magazine Discourse, 5(31) (2019) pp. 64-69. 
[2] V.I. Mukomel, Migrants in the Russian Labor Market: Employment, Mobility, Intensity and Wages in: Statistics and Economics, 6 (2017) pp. 69-79.

[3] A.G. Tomaska, Demographic factors of social adaptation of students - rural migrants of the indigenous small-numbered peoples of the North (on the example of the Republic of Sakha - Yakutia) in: Bulletin of the Kalmyk Institute for Humanitarian Research RAS, 1 (2015) pp. 141-146.

[4] Lyudmila Vasilievna Korel, Sociology of adaptations: issues of theory and methodology in: RAS, Sib. department, Institute of Economics and Organization of Industrial Production - Novosibirsk: Nauka (2005) p. 8.

[5] Nogan Vyacheslavovna Badmaeva, Experience of labor migration of rural residents of Kalmykia (based on in-depth interviews) in: Bulletin of KIGI RAS, 3 (2020).

[6] O.L. Lushnikova, Social adaptation of rural migrants: theoretical and empirical aspects of the study in: Discussion, 6(91) (2018) pp. 48-59. DOI: https://doi.org/10.24411/2077-7639-2018-10015.

[7] Yu.G. Bychenko, V.L. Shabanov, Modern migration of the rural population: features, directions, consequences in: Bulletin of the Saratov State Social and Economic University, 2 (2012).

[8] D.S. Brazevich, Sociological analysis of the cultural aspects of interethnic interaction in the urban environment in the context of the relationship between the identities of migrants and the host community in: Russia in the era of revolutions 19172017: an experience of understanding Russian identity: Collection of scientific articles, St. Petersburg, December 06-08, 2017. - St. Petersburg: Religious organization - Spiritual Educational Organization of Higher Education St. Petersburg Theological Academy of the Russian Orthodox Church (2018) pp. 259-262

[9] L.G. Ivanova (Lamot), A.I. Kazankov, O. L. Leibovich, A.S. Chernousov, Integration of migrants into the Perm urban environment: cultural and linguistic aspects: monograph, Perm State Institute of Culture (2015) p. 189.

[10]F. Riggs, Aspects of the content of ethnicity in: Ethnicity and Politics (2000) p. 10.

[11]E. Hobsbawm, Nations and Nationalism After (1998) p. 249.

[12]D.P. Karanov, Migrants and the host society: the cultural aspect of interethnic relations in the urban environment in: Politia: Analysis. Chronicle. Forecast (Magazine of Political Philosophy and Sociology of Politics), 1(68) (2013) pp. 24-35.
[13]R.K. Merton, Social structure and anomie in: Sociology of power, 4 (2010).

[14] E.V. Balatsky, N.A. Ekimova, Public administration tools: forecasting vs design in: Manager, 12(1) (2021) pp. 18-31. DOI: https://doi.org/10.29141/2218-5003-2021-12-1-2.

[15] Dmitrii Yadranskii, Viktor Chigrin, Elena Chumak, The economic, social, and spiritual efficiency of the economic system: approaches to assessment in: Baltic Journal of Economic Studies, 9(4) (2018) p. 388-386. DOI: https://doi.org/10.30525/22560742/2018-4-4-380-386. 